1. En totes les èpoques de la historia d'una llengua resulta dificil de constatar, o si mes no d'entreveure a traves de la llengua literâria, quin es el veritable estat de la llengua parlada. Aquesta dificultat, palesa en I'anomenat llat1 vulgar, es troba tambe a les liengtles romàniqués.

Com que no coneixem el llati parlat, ja que no existeixen textos en vulgar, perỏ si que coneixem, i molt be, el vessant

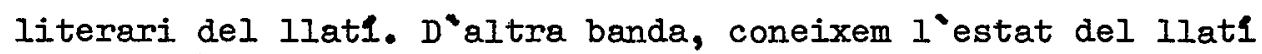
parlat nomes a partir de les peculiaritats que, en el llat1 literari, son violacions de la norma que ens es coneguda a traves dels textos literaris llatins, violacions que es poden trobar en alguns textos literaris, $i$ des de Plaute, en inscripcions o provinents de les advertències dels gramàtics. Ia nostra coneixensa del llati parlat es limitada tot $i$ que il'Iuminada, certament, per la situaci6 actual, o be pel passat de les llengiues româniques. Ies reconstruccions, sobretot pel que fa al lèxic - menys en el camp morfosintàctic -, a base de l'estat d'un fenomen en el romanc actual, ens pot convèncer de I'existència, encara que no documentada, d'una paraula, d'una forma, del caràcter d'un so, postulat solament a partir de tots $\circ$, si més no, de la majoria de llengïes romàniques.

El perlode de I'Humanisme \&s època d'un creixent interès pel llat1, es mes encara: es el perlode de desig de fer reviure el llati o, pel cap baix, d'apropar-se tant com sigui possible a I'elegància estillstica dels escriptors clàssics. Es, tambe,

I’autor agraeix a Rosa Maria Delor i Muns la traducció al catala $i$ els seus consells pel que fa al tema tractat. 
el temps en què aquesta tendència, la llatinizant, influeix sobre la llengua, contrastant el desenvolupament popular. ${ }^{1}$

2. Observem aqui les subordinades objectives que en els textos catalans llatinitzants resulten, sovint, implicites amb I"infinitiu. ${ }^{2}$ Sovintegen, tambe, amb I'elegant construccib d'infinitiu amb acusatiu, mentre que un bon percentatge de les subordinades es troben en forma expllcita, es a dir, introdurda per la conjuncis que. No cal insistir en el fet que les construccions amb infinitiu han d'Esser literàries i no populars: una comprovacit ens es fornida pel romanès, llengua romànica considerada conservadora per molts trets, la qual gairebe no coneix, en les subordinades objectives, les construccions amb

1 Ia llengua italiana pot ésser un exemple convincent. Se sap que la tradicio llatina a Itàlia fou més forta que a d'altres parts de la Romània. Als inicis de la literatura italiana podem constatar en els textos dues tendències: la literària, llatinitzant en el Decamer,, i la popular, representada pel Novellino. Vegis la meva comunicacis en el XVIè Congres internacional de lingllstica i filologia romaniques. Ciutat de Mallorca 1980, "Subordinate oggettive e oggettive volitive negli antichi testi letterari italiani" ( $d$ 'imminent publicacib a les Actes del congres).

Moll, parr. 547 i 548: - En catalkn antiguo, sobretodo en los autores más clásicos $\mathrm{y}$ de formacion humanlstica, era frecuente el uso de las oraciones que en grambitica latina se llaman "de infinitivo": Solament I home deim haver ànima substantiva (Metge) .... Mucho mḱs corriente en el catalán antiguo, $\boldsymbol{J}$ el f́nico normal en el moderno, es el enlace mediante la conjunción que, de la oración sustantiva complemento directo ... 
infinitiu. Aquesta forma ha romàs relegada a 1 exiorc estil administratiu, $i$ sols en oracions objectives volitives del tipus $\hat{1}$ i ordonam a sü prezenta imediat 'li manem de presentarse d'immediat', la qual cosa pot, fàcilment, esser interpretada com una influència del francès.

3. Pel que fa al català antic convê de destacar que els primers textos no posseeixen massa subordinades objectives: el caràcter dels esmentats textos, que son documents juridics, documents religiosos $i$ sermons, impossibilita un tis ampli de les objectives, les quals, mes que cap altra forma oracional, substitueixen les oracions paratàctiques dels diàlegs, quan un diàleg d'aquesta mena ve donat en forma de resum, en un discurs indirecte. De tota manera trobem regularment una subordinada explicita, ad es.:

que nos trobam que Ioachim sos paire et Anna sa maire avion estat gran termini esséms, e no podion aver enfant

serm6, XI-XII s., Bulbena, pag.27

E regonosc que tenc a feu del bispe de Nemse lo castel de Monpesat

$$
\text { doc. a. } 1174 \text {, Bulbena, pag. } 35
$$

fem-vos sabèr que Nòs avèm regonegut al Régne de Valencia. $E$ perzò quar Nòs avèm vist que 1 Régne no ha son compliment $d$ 'omens ni de gent

$$
\text { doc. a. 1270, Bulbena, pag. } 54
$$

nos ha scrit lo dit Ffrancesch e fans saber que lo dit Rey de Tunyg ha haut fort gran plaer dela venguda del dit noble et $l i$ ha fet fort honorable acullyment

$$
\text { doc. 8-10-1402, Moscati, pag.141 }
$$


Amb tot, trobem als primers segles de literatura en català, esporàdicament, la construccio d'infinitiu amb acusatiu, de vegades, certament, darrera un verb de percepcio sensorial, $i$ tambe, alguna vegada, sense objecte quan aquest es un pronom:

Emperò vistes aqueles esteles, e profecies e
escriptures, coneguéren aquel esser fil de Deu
Fra Pere Marsili, Bulbena, pag. 93

com lo rey lo veu venir axi sutren

Russel, pag.119

qui cuydaven ésser morts com venlen en ta má Ramon Muntaner, Bulbena, pag.119

4. Per tant interessa d'una manera especial I'obra de dos escriptors catalans, creadors en certa mesura de la llengua literària. Ens referim a Ramon Liull i a Bermat Metge. L'interès resulta més justificat quan a 1 'obra de Metge es constata un ts abundos de la construccio d'infinitiu amb acusatiu. 3

Pel que fa a la llengua d'ambdós autors no pot esser comparada mitjançant el tipus d'oposicio que fèiem, per a l'italià, entre el Novellino i el Decamero. No. No podem titllar Ramon Ifull de representant d'una llengua popular: la matèria mateixa del seu discurs no ho permet, es a dir, que un escriptor popular mai

3

- Mes en temps de Metge la construccib infinitiva era igualment esmerçada ab verbs d'enunciacio y $a b$ altres qui no s'escauen dins aquesta nomenaci反, lo règim directe dels quals no's concreta al subjecte"del infinitiu, ans es realment tota la proposici6 infinitiva complerta. Aytals construccions, qui trahexen la gentil influencia llatina, son abundosissimes en nostre autor $y$ en cambi avuy son resoltament rebutjades en estil planer, A. Par, pag. 297; amb exemplificacib abundosa. 
no discutiria sobre "I offici qui pertany a cavaller". 4

ILull empra formes implicites del verb, empra l'infinitiu, el gerundi, el participi absolut. Utilitza I'infinitiu complint diverses funcions ( $\operatorname{com}$ a mer substantiu, subjecte amb verbs impersonals, element de perlfrasis verbals): ¿Has vist null cavaller gui son castell no vulla recobrar?; e soferl que tot cavaller gui am ésser en ordre de cavalleria lo pusca translatar; anava a la cort per esser adobat a novell cavaller, Iribre del ordre de cavalleria, II, 30; Pròleg, 14 i 3. Tanmateix es troben exemples amb 1 a construccio d'infinitiu amb acusatiu (si be conservant la terminologia llatina):

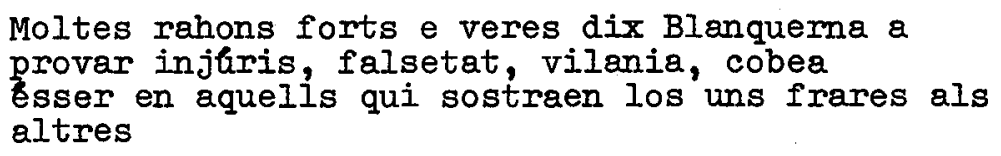
altres

Blanquerma, Ant., p.14

per tal que cogità lo poder de Deu ésser poder6́s

Blanquerma, Ant., p.20

e aytant com po poder es major d'aytant ts signifficat en Deu esser major bonea

Del gentil e dels tres savis, Bulbena, pag. 89

En alguns exemples, el subjecte de l'infinitiu (ja que, a partir d'ara, no podem continuar parlant d'acusatiu o nominatiu) resulta anticipat; aixi

de la honor qui's cove tsser feta a cavaller Cavalleria, Pròleg, Intr.

4 s'expressen amb molta agudesa Badia $i$. Margarit i Francesc Moll a 0.E., pag. 1305: - ... dues copstants: una barreja curiosa de llatinisme i popularisme linglistics. 
Abat cove esser acustumat de menjar nostres viandes, e de seguir covent, e que aja nostres custumes

$$
\text { Blanquerna Ant., p.24 }
$$

mas 1 abat dix que lo monge qui hauria aquell ofiçi, convenia esser gran clergue

$$
\text { Blanquerna Ant., p.29 }
$$

De vegades el subjecte de la subordinada es idèntic al de la principal: contràriament al sistema llat1, I'estructura catalana no el representa sota la forma de pronom:

iqual cavaller acostumat a fer torts $e$ injuries cuida ésser en l'ordre de cavalleria?

$$
\text { Cavalleria, VI, } 6
$$

Tambl podem considerar com herència de I'acc.c.inf. llat1 les estructures verbals amb el verb fer:

si fas cavaller home que no sia de paratge

tu fas ésser contraris paratge e cavalleria

en go que fas

$$
\text { Cavalleria, III, } 8
$$

On, enaixl con vergonya fa ésser hom vergonybs

$$
\text { Cavalleria, V, } 4
$$

Pero la major part de subordinades que depenen de verba sentiendi et dicendi són expllcites:

Creure que Jesuscrist fos concebut de Sant Esperit .... ... Tot hom ès tengut que crea aquests catorze articles

$$
\text { Cavalleria, IV, } 5
$$

e digueren que no era custume de lur ordre que elegisen abat

$$
\text { Blanquerna Ant., p.23 }
$$


és prop considerar que Deus pusca no ésser si be ès Cavalleria, IV, 5

Manament ts de lei que hom no sia perjur Cavalleria, II, 32

no es digne que cavalleria lo reeba en son ordre Cavalleria, III, 18

5. Ia llengua de Bernat Metge aixl com I'ts de I'infinitiu foren examinats per Anf6s Par. ${ }^{5}$ Podem repetir els exemples de Par, 884:

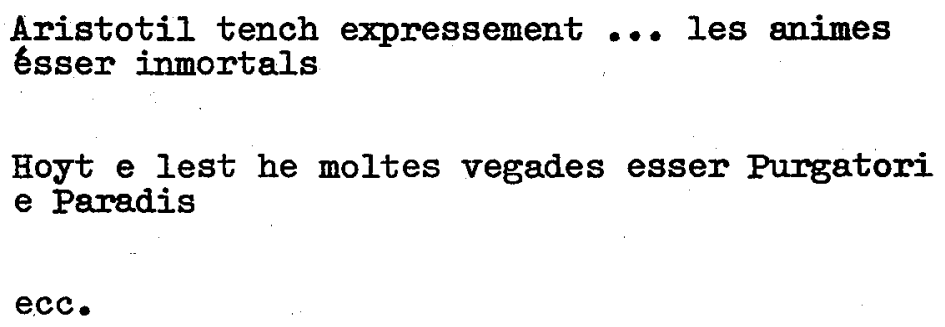

Aquesta estructura es freqlient, però no predominant (cfr. tambs Par, 880), perque hom troba mts sovint oracions subordinades, introduides per que

E enten que sots viu

e no veya que esperit ne altra cosa lurs isqués del cors

Mas tostemps he credut que ço que hom diu esperit, o ènima, no fos als sino lo sanch.

5 Cfr. Anfos Par, cit., parr. 786-827; sbbret6t 815 i, tambe, 880 . 
Si tenim en compte I'ts de I'estructura llatina acc.c.inf., la qual ts molt mes freqient a Metge que no pas a IIull, ens adonem que el pes de la tradicib llatina augmenta sensiblement a Bernat Metge.

6. En analitzar les subordinades objectives, constatem que, a Ia llengua contemporània, tenen forma expllcita, es a dir, I'estructura heretada o reintroduida del llat en els textos medievals ha desaparegut, llevat dels casos en els quals 1 'acusatiu amb infinitiu es regit per un verb de percepcib sensorial, del tipus moltes vegades he vist morir homens e besties e ocells (Metge).

Ben al contrari, a les subordinades objectives amb matis de desig, que anomenem volitives, del tipus Us preguem vivament de venir-nos a trobar; T'ordeno.d'acceptar el càrec, I'infinitiu no apareix, o quasi. 6

Trobem subordinades introduides per la conjuncib que en textos de caràcter administratiu, en certes de caire oficial:

Nós en Jacme, ... volèm e mandam a totz los rics-homens, e als cavallers e a totz los homens que fassen homenatge e sagrament al Enfant en Jacme fil nostre

$$
\text { doc. a. 1292, Bulbena, pag. } 62
$$

Puis ... nos estan(t) en Leyda, vingues devant Nós, nos cuydan( $t)$ que venguessetz aparellatz d'anar en mon servici, e pregam e manan-vos que-ns seguissetz en lo viatge

$$
\text { doc. a. 1273, Bulbena, pag. } 57
$$

6 Vegis Badka i Margarit, parr. 221, 1c: - complemento directo del verbo; suelen llevar infinitivo como complemento de los verbos de percepcion, voluntad, pensamiento .... us proposem tornar a peu. 
E quant vénch a I'alba, fo emprès que hoissem les misses ... E oides les misses ... dixém que s'armassen tóts

$$
\begin{aligned}
& \text { Conquesta de Valencia, a. } 1283 \text {, } \\
& \text { Bulbena, pag. } 66
\end{aligned}
$$

E enviam per Al1-Albaga que tornás denant Nós,

e dixem-hi que dixés per que éra vengut

Bulbena, pag. 73

lo dit senjor Rey ... donk ordre que ... besant peus et mans juraren don Ferando per primogenit Russel, pag.193

vench vers lo cavaller, lo qual lo pregà que $1 i$ digués com era mort lo senyor de Mombrt Russel, p.195

De Ramon Ifull podem citar perlodes amb verbs, a la principal, dir, pregar, consellar, plaure:

I'escuder pregà lo cavaller que li dixes

1 ordre de cavalleria

$$
\text { Cavalleria, Prolèg, } 8
$$

Sènyer, sì a vós plasia que 'm dixtssets l'ordre de cavalleria.

$$
\text { Cavalleria, Prolèg, } 10
$$

7 Constaten Badla $i$ Margarit i Francesc Moll per 1 'tas de 1 'infinitiu, 0.E., pág.1338/40: - Ramon ITull expressa sistemàticament en forma personal conjugada moltes situacions verbals que avui mes aviat corresponen a I'infinitiu. Aquest tret es exemplificable potser com cap altre, i creiem que, almenys en la sintaxi verbal, es el que mes exactament retrata I'autor. - I'citen: - les paraules que ... dix al pastor per so que ' 1 consolas; pot haver creanca que haja salvacib; ts indigne que sia papa; qui creyen en lo seu aveniment ans gue morissen. 


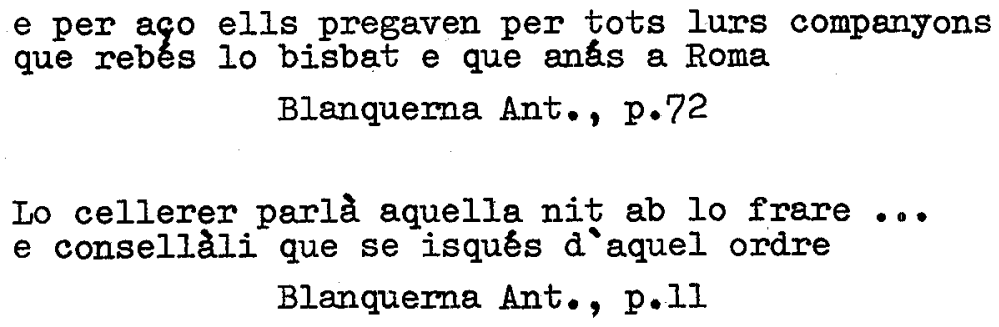

Tel i com passa amb IJull, Metge generalment usa la subordinada expl1cita:

$$
\begin{aligned}
& \text { set dies stigui a la porta } \\
& \text { pregant Cerbero que lexas tormar } \\
& \text { Somni, Lo ters libre }
\end{aligned}
$$

mon senfor me ha manat que io prenga aquesta infanta

$$
\text { Valter i Griselda }
$$

manant li que no parlas

ibid.

Tanmateix, susciten un interes particular exemples on apareix I'infinitiu amb un verb modal (manar, deixar, prohibir, etc.). Un text particularment valubs es Valter $i$ Griselda, on hi podem llegir (cfr. tambe l'exemple del Somni adés citat, amb verb lexar):

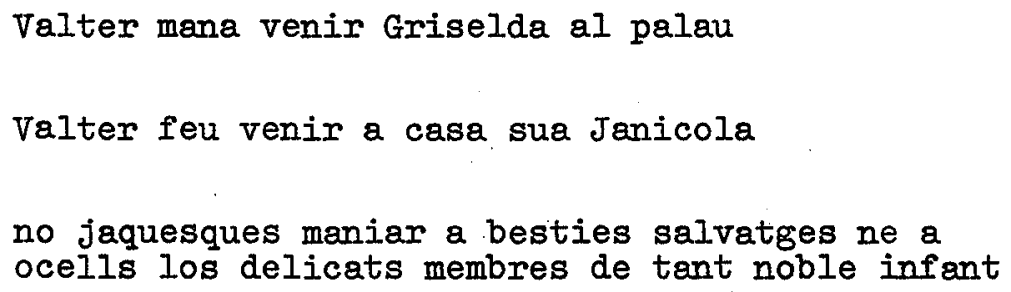

Aquestes estructures tot $i$ que no son heretades del 1lati literari, ens descobreixen el gust de 1 'autor $i$ una certa inclinacif per 1 'Gs de les formes implicites deI verb $i$ demonstren, consegilentment, una tendència llatinitzant. 
7. Aitals tendències resulten més fortes a Metge que no pas a LIull $i$ a d'altres autors menors. L'oposicis entre Metge, "primer estilista catala" (Par) i ILull no es en res equiparable amb que feiem entre Boccaccio $i$ el modest autor del Novellino: Itull $i$ Metge demostren en emprar les estructures implicites les naixents aspiracions humanistiques, $i$, alhora, amb dos en construir el periode recorren, sobretot ILull, sovint a les subordinades introduĩdes per un gue amb el verb en forma personal, $i$ amb aixb reten testimoniatge de la continultat en la manera de construir el periode en l'anomenat llati vilgar, 0 sia, parlat, pel que es desprèu que la forma de construir el periode es pot postular: I'ts de les formes infinitives, elegants, demostra una altermativa, opcis estilistica, pròpia del llat1 literari $i$ per tant aliena a la parla popular. En les llengües romàniques ha prevalgut la tendència popular eliminant estructures del tipus acusatiu amb infinitiu que resten com un senyal d'aspiracions estillstiques, d'elegància.

Es curios, i contrari a 1 'us del 1lat1, que les llengües romàniques coneixen I'infinitiu en les objectives volitives el catala I'admet com altermativa de la subordinata explicita. I sembla esser, que troba les primeres mostres daquesta tendencia - una altra vegada com innovacio estilistica i literària, aliena e la parla espontània - a la llengua de Metge.

\section{OBRES CONSUITADES}

Bulbena: Crestomatia de la llengua catalana, Bulbena i Tosell, I, Barcelona 1907

Russel: Medieval Catalan Iinguistic Text, by Paul Russel-Gebbet, Oxford 1965

O. E.: Ramon IIull, Obres essencials, I-II, Barcelona 1960 Ant.: Antologia de Ramon IIull, Barcelona 1947 
Cavalleria: Raimondo Iullo, Il libro dell'ordine della cavalleria, Testo catalano con versione introduzioni e note del prof. Giovanni Allegra, Roma 1972

Metge: Obra completa de Bermat Metge, Barcelona 1975

Moscati: Per una storia della Sicilia nell'eta dei Martini, Messina 1954

Moll: Francisco de B. Moll, Gramatica hist6rica catalana, Madrid 1952

Badia i Margarit: Antonio M. Badia Margarit, Gramktica catalana, Madrid, 1962

Par: Anfos Par, Sintaxi catalana, Beihefte zur ZRPh, 66, Halle 1923

\section{Povzetek}

\section{ODVISNIKI Z INFINITIVOM V STARI KATAIONŠČINI}

Za vse dobe jezika velja, da z veliko težavo ugotavljamo, kakšen je bil govorjeni jezik tístega časa. Za latinščino je ta težava nesporma, saj romanski jeziki predpostavljajo eksistenco tako imenovane vulgarme latinšcine, se pravi neke latinščine, ki ne sledi docela normi, veljavni za literarno latinščino.

Tudi za starejse faze romanskih jezikov se zdi ugotavljanje jezikovne realnosti pomembno, saj je mogoče nek jezikovni pojav bolje osvetliti, ðe ga opazujemo razvojno, če gledamo, s kakšnimi jezikovnimi sredstvi je nek pojem, neko miselno enoto izražala latin̋̆cina. Doba humanizma, se pravi, doba rastočega zanimanja za "klasično" latinšino, zelja za oživljenje tiste norme, ki jo vsiljujejo literarni teksti, je tista kritična točka, vsaj $\checkmark$ veliki večini romanskih jezikov, ko se težnja $k$ naravnemu izražanju bije z zaverovanostjo $\mathrm{v}$ posnemanje latinskega vzora. Misel, da je bila taka težnja v Italiji najbolj močna, potrjuje dejstvo, da je italijanščina dobila pečat literamosti, skoraj bi rekli latinskosti, ravno $v$ dobi prebujajočih se humanističnih teženj; pečat, ki je francoščini, na pr., popolnoma tuj. Na začtkih humanizma je mogoče zaslediti vitalijanski knji¿evnosti dva nasprotujoča si tokova, Ijudskega, kot je viden $\checkmark$ zbirki novel II Novellino, in pa $v$ latinsko prozo zazrtega, kot ga izžareva Boccacciov Dekameron.

Ko avtor opazuje gradnjo zloženega stavka v romanskih jezikih, zlasti povednih odvisnikov, $\mathrm{ki}$ so $\mathrm{v}$ latinščni izraženi z značilno konstrukcijo akuzativ z infinitivom, ne želi reči samo tega, da je gradnja stavka z eksplicitno glagolsko obliko, 
uvedeno $\mathrm{z}$ veznikom quid, quod in podobno, izrazito ljudska, in torej dokaz za ljudskost nekega literarnega teksta, gradnja zloženega stavka z implicitnim odvisnikom pa dokaz za "latinski" karakter kakega jezika. Avtor misli, da izražanje z brezosebnimi glagolskimi oblikami ni ljudsko, da je bilo lastno zgolj pisani, literarmi latinščini, ne pa govorjeni: $v$ to ga uverja tudi dejstvo, da eden od romanskih jezikov, romunščina, ki je sicer $v$ nekaterih pojavih močno konzervativen jezik, konstrukcij $z$ infinitivom skorajda ne pozna: edinole $v$ suhem administrativnem slogu, $v$ izrazito uradnih formulacijah tipa "Ukazujem vam priti ..." se taka konstrukcija pojavlja in uveljavlja.

V katalonskih tekstih XII. - XV. stoletja se iz latinščne podedovane implicitne konstrukcije pojavljajo samo v pravi literaturi, torej v pisanju s stilističnimi ambicijami. Dva katalonska pisca Ramon IIulI in Bernat Metge, Boccacciova sodobnika, sta posebej pomembna: veljata, tako kot Boccaccio za italijansko prozo, za začetnika umetniske proze v katalonščini, in zlasti Metge se velikemu italijanskemu pisatelju tudi po svojih stilističnih težnjah močno približuje. Njegovo najboljšo novelo Valter in Griselda bi prav lahko šteli v krog najboljsih novel 14. stol. Oba katalonska avtorja poznata implicitne glagolske oblike, infinitiv, gerundij, poznata absolutni particip, uporabljata latinsko konstrukcijo akuzativ $z$ infinitivom; in vendar so eksplicitni odvisniki, uvedeni z veznikom, mogo bolj številni.

V objektnih odvisnikih, kjer je sočasno izražena želja, nobeden od katalonskih avtorjev, kakor tudi ne teksti anonimmin piscev ali pisarjev, ne pozna infinitiva, pač pa zmeraj samo eksplicitni odvisni stavek. Zdi pa se, da so prve konstrukcijo tega tipa z modalnim glagolom zaznavne že $v$ jeziku B. Metgeja. Naj citiramo iz novele Valter in Griselda: no jaquesques mamiar a besties salvatges ne a ocells los delicats membres de tant noble infant 'ne dajte, da bi divje zivali ali ptice pozrle nezne ude tako plemenitega otroka'. 